\title{
SEMELHANÇA ENTRE TABAGISTAS E INFECTADOS POR COVID-19
}

\author{
SIMILARITY BETWEEN SMOKERS AND COVID-I9 INFECTED
}

\author{
Lyon José da Costa Pereira ${ }^{1}$ \\ Mateus Felipe Rodrigues ${ }^{2}$ \\ Victor Oliveira Silva ${ }^{3}$ \\ Arilton Januário Bacelar Júnior ${ }^{4}$
}

RESUMO: O agravamento dos quadros pulmonares tanto em tabagistas quanto em pacientes com comorbidades respiratórias tais como infecção por Covid-ı, em ambos possuem semelhanças incluindo receptores, enzimas e sintomas. No entanto os fumantes possuem quadros mais agravantes devido as doenças que o tabaco já induz a saúde do indivíduo além de terem um maior risco ao se infectarem pelo vírus SARS-CoV-2 em relação aos não fumantes. Várias instituições de pesquisas relacionam o tabaco(relacionando todos os tipos) como fator agravante a infecção pelo novo coronavírus. A nicotina, uma das principais substâncias presente no cigarro, é estudado como fator de proteção ao vírus. Está relacionado também os fumantes passivos, ou seja, aqueles que são ex-fumantes ou até mesmo aqueles que nunca fumaram, podem ter fatores agravantes.

Palavras-chave: Covid-ı. Tabaco. Fumante.

ABSTRACT: The worsening of pulmonary conditions both in smokers and in patients with respiratory comorbidities such as infection by Covid-19, both have similarities including receptors, enzymes and symptoms. However, smokers have more aggravating conditions due to the diseases that tobacco already induces the health of the individual in addition to having a greater risk of becoming infected with the SARS-CoV-2 virus in relation to non-smokers. Several research institutions list tobacco (listing all types) as an aggravating factor for infection with the new coronavirus. Nicotine, one of the main substances present in cigarettes, is studied as a protective factor against the virus. Passive smokers are also related, that is, those who are ex-smokers or even those who have never smoked, may have aggravating factors.

\footnotetext{
'Formação acadêmica: Discente do curso de Graduação em Biomedicina da Faculdade Única de Ipatinga. ${ }^{2}$ Formação acadêmica: Discente do curso de Graduação em Biomedicina da Faculdade Única de Ipatinga. 3Formação acadêmica: Discente do curso de Graduação em Biomedicina da Faculdade Única de Ipatinga. ${ }^{4}$ Formação Acadêmica: Farmacêutico/Bioquímico pela Universidade de Marília. Professor do curso de graduação em Biomedicina das matérias de Farmacologia, Psicofarmacologia, Imunologia Básica, Imunologia Clínica e Parasitologia. Instituição de Ensino: Faculdade Única de Ipatinga
} 
Keywords: Covid-19. Tobacco. Smoker.

\section{INTRODUÇÃO}

A atual pandemia causada pelo coronavírus 2019 (Covid-I9), teve início em II de março de 2020 tendo o reconhecimento da Organização Mundial de Saúde(OMS). (CARVAlHO MALTA, 2020; Patanavanich R, 2020). No Brasil, o primeiro relato de infecção da doença foi no estado de São Paulo, em 26 de fevereiro de 2020 (CARVALHO MALTA, 2020; CRODA, 2020). Segundo a OMS (WHO, 202I) em 3 de janeiro de 2020 à 13 de maio de 2021, houve mais de 15 milhões de casos confirmados e com mais de 425 mil mortes em território brasileiro.

O uso do tabaco é recentemente reconhecido como uma doença, nos dias de hoje é considerado uma doença neurocomportamental devido a dependência da nicotina, no qual os usuários podem ter diversos sintomas como depressão ansiedade, baixa autoestima (MALTA, 202I; RAMOS, 2021).

Diante do tabaco atuar diretamente no sistema respiratório, tanto nas cavidades quanto no pulmão propriamente dito, sendo similar aos locais donde o vírus SARS-CoV-2 se insere e progride. Então essa revisão de literatura tem como principal fator abordar a similaridade entre as pessoas tabagistas infectadas por Covid-ı.

\section{MATERIAL E MÉTODOS}

O presente estudo é uma revisão bibliográfica, partindo das pesqiuisas de outros estudos disponíveis na literatura, acerca do assunto foram identificados por busca nas plataformas: Scientific Electronic Library Online (SciELO), Google Acadêmico, PubMed, dados da Organização Mundial de Saúde (OMS), e artigos publicados nos períodos anuais de 2019 à 2021.

As buscas foram feitas recorrendo os descritores: "Covid-19 em fumantes; tabagismo e riscos pulmonares, relação SARS-CoV-2 em fumantes”. Foram selecionados 
artigos utilizando os seguintes critérios: artigos originais, recentes e indexados em plataformas reconhecidas, que abordassem sobre o tema escolhido.

\section{DESENVOLVIMENTO}

$\mathrm{O}$ ato de fumar conhecido como tabagismo foi e ainda é considerado um grave problema de saúde pública, devido as comorbidades de complicações da capacidade do indivíduo ao respirar. Quando se fala em fumantes, logo vem em mente o cigarro como único tabaco, mas vale ressaltar que estão incluídos os dispositivos eletrônicos para fumar(DEFs) à boca e os narguilés (SILVA, 2020; WHO Framework Convention on Tobacco Control, 2019). Além do mais, o consumo de tabaco(cigarro) aumenta os riscos de infecções virais e bacteriana, podendo desenvolver doença pulmonar pneumocócica invasiva, influenza e tuberculose, cardiopatias, diabetes, hipertensão arterial e câncer. Ao fumar a pessoa corre sérios riscos para doenças e infecções respiratórias graves, por motivos nos quais surgem mudanças estruturais no trato respiratório além da redução da resposta imunológica do organismo (DE ARAÚJO, 2020).

Os efeitos que são causados pelo tabaco estão documentados em várias literaturas cientificas. De acordo com a Organização Mundial de Saúde(OMS), relata que há em média I,3 bilhões de fumantes no mundo, sendo estimado em 8 milhões de mortes anualmente (DE ARAÚJO, 2020; World Health Organization. Preventing noncommunicable diseases, 2020).

Estudos mostram que em pacientes acometidos com covid-19 possui I4 vezes maior chance de progressão negativa(até a morte) em comparação com aqueles que são fumantes. Sendo assim os indivíduos fumantes possui um prognóstico a evoluírem para quadros piores(incluindo o óbito). E levado em consideração que o tabagismo pode ser um fator de risco em pacientes com Covid-ı́ com manifestações graves da doença (Liu W, 2020 ; SILVA, 2020; SZKLO, 2020). 
Dentre os pacientes infectados com Covid-ıg e fumantes, a maior parte são homens. Então isso leva em consideração de que os homens fumam mais ao se comparar com as mulheres (SZKLO, 2020).

Já é de conhecimento da maioria da população alguns fatores de riscos em pacientes infectados pelo vírus SARS-CoV-2(Covid-r9) tais como: idade avançada; pessoas que já possui alguma problema respiratório, como a asma e bronquite; cardiopatas; hipertensos; diabéticos; além daqueles que possuem baixa imunidade. Contudo, é importante acrescentar um grupo de risco que seria os tabagistas (Sardu, C, 2020 ; SILVA, 2020).

Como os tabacos em geral são usados através de pegar o produto com as mão, se não há uma higienização adequada das mãos, pode sim se tornar um fator de transmissão viral para o Covid-19. Ademais, possui o compartilhamento de tabacos, assim como os narguilés que são muito populares entre os jovens, que gostam de compartilhar os bocais, facilitando o contágio (SILVA, 2020).

Estudos em células humanas demostram que o tabaco aumenta a gravidade do quadro pulmonar como a infecção por influenza, que aumenta a replicação viral devido a suspenção de mecanismos antivirais incluindo alterações de citocinas nas células com papel de imunidade inata da mucosa. Pode-se acusar o tabagismo como culpado em aumentar a expressão da enzima conversora de angiotensina 2(ECA2), sendo receptor do SARS-Cov-2 em abundancia nos pneumócitos tipo II e no tecido alveolar (Brake SJ, 2020; SILVA, 2020).

Relacionando o Covid-ıg com o tabagismo, ambos apresentam disfunção endotelial além da elevação de radicais livres. Vale acrescentar que o Covid-ı9 possa desenvolver danos em células endoteliais devido alguma lesão já acometida por causa do tabaco (SILVA, 2020).

Níveis elevados de proteína $C$ reativa(PCR) e dímero-D, pode ser observado em pacientes infectados por Covid-19 e em fumantes (Cai H, 2020; SILVA, 2020). Um estudo feito pela Universidade de Oxford, na Inglaterra, onde foi conduzido algumas pessoas (independente do sexo) fumantes e não fumantes a realizarem exame de RT-PCR(reversetranscriptase polymerase chain reaction) para o coronavírus. Os resultados mostraram que 
aqueles que são fumantes ativos possuem metade da chance de testarem positivos comparando-se os não fumantes, isso se dá ao fato de que os fumantes já possuem alguma comorbidade respiratória (de Lusignan S, 2020; SZKLO, 2020).

Pesquisas feitas na França indicam que a nicotina possui efeitos protetores para o coronavírus. Ao associar os efeitos biológicos plausíveis de que os tabagistas possuem uma expressão maior da enzima $\mathrm{ACE} 2$, sendo este receptor associado à Covid-ı9 (Brake SJ, 2020; Changeux JP, 2020). Formando-se hipóteses de que a nicotina apresenta um fator protetor na infecção por coronavírus, devido ao vírus SARS-Cov-2 envolve receptores nicotínicos de acetilcolina das células. Contudo, de acordo com o Instituto Nacional do Câncer(INCA) ressalta que o uso de nicotina é altamente prejudicial à saúde humana (SZKLO, 2020; Tindle HÁ, 2020).

A exposição à fumaça de cigarros; narguilés e de DEFs, aumenta a inflamação na mucosa respiratória além da expressão de citocinas inflamatórias podendo surgir fatores de necrose tumoral; no qual irá aumentar a permeabilidade da barreira alvéolo-capilar, surgindo edema e espessamento septal junto com hipersecreção da mucosa, tendo comprometimento do transporte mucociliar (DE ARAÚJO, 2020).

Tanto em fumantes quanto em pessoas contaminadas por Covid-19 possuem elevação das interleucinas IL-2 e IL-7 e fatores de necrose tumoral, que são relacionadas a síndrome de tempestade de citocinas no qual são responsáveis por lesões endoteliais naqueles que apresentam forma grave da doença (DE ARAÚJO, 2020; Patanavanich R, 2020).

Ao fumar, o indivíduo inala a cada tragada volume considerável de monóxido de carbono( $\mathrm{CO})$, tendo afinidade pela hemoglobina das hemácias gerando corboxiemoglobina resultando em hipoxia. Essa exposição a toxinas do tabaco gera disfunção endotelial e inflamação crônica mediado por citocinas. $\mathrm{O}$ mesmo acontece em aqueles contaminados pelo vírus SARS-CoV-2 (DE ARAÚJO, 2020).

A fumaça gerada pelos tabacos possui em sua composição mais de sete mil substâncias químicas de classes diferentes. Sendo um desses componentes a nicotina que 
causa dependência química e atua como agente promotor na carcinogênese, fazendo com que o organismo produza peptídeos de angiotensina 2, que induzirá a vasoconstricção (CAVALCANTE, 2020). Sobre os efeitos de substâncias tóxicas presentes no tabaco, a hipoxia nos fumantes possui uma evolução do mecanismo fisiopatológico que se assemelha ao observado em pacientes com Covid-ıg. Porém a evolução do coronavírus é mais lenta, devido a disfunção do endotélio dos vasos sanguíneos; inflamação crônica e por ações de citocinas. Então, contribui para um estado de hipercoagulabilidade por causa do aumento de agregação plaquetária, aumento de fibrinogênio pelo fígado (responsável regulador do sistema hemostático). Por isso os fumantes tendem a ter este desequilíbrio na coagulação causando riscos de trombose. É plausível caracterizar os fumantes infectados pelo vírus SARS-CoV-2 serem mais vulneráveis ao agravamento do quadro pulmonar. (Barua RS, 2009) (CAVALCANTE, 2020).

Estudos feitos sobre a permanência de aerossóis derivados do tabaco podem ficar em até 3 horas na atmosfera, com isso levamos a hipóteses de que também é plausível considerar os fumantes passivos, ou seja, aqueles que respiraram os componentes tóxicos do cigarro que estejam no ambiente. Considerando a o aumento de partículas de 2,5 micra $\left(\mathrm{PM}_{2,5}\right)$ e $\mathrm{CO}$ na atmosfera, há possibilidade do aumento da expressão ACE2 nos pulmões dos fumantes passivos, que resulta em uma vulnerabilidade menor para complicações do Covid-19 (CAVALCANTE, 2020; Chiusano ML, 2020; University of California Merced 2020).

O tabagismo é considerado o principal fator para doença pulmonar obstrutiva crônica (DPOC), tendo um índice em território brasileiro de $88 \%$ de óbitos em homens e 81\% em mulheres (SILVA, 2020; SZKLO, 2020).

Em fumantes acometidos com Covid-19, possuem cerca de 3,25 vezes mais chances de chegarem a quadros mais graves da doença (SILVA, 2020). De acordos com a revisão sistemática, houve uma pesquisa de dados publicados em março de 2020, mostra que cerca de $38,5 \%$ dos fumantes possui maiores riscos do que aqueles não fumantes; Além disso, 
pacientes fumantes possui $45 \%$ de apresentarem complicações severas relacionadas a infecção por Covid-ı9 (SZKLO, 2020).

\section{COSIDERAÇÕES FINAIS}

A semelhança entre os tabagistas e os infectados por Covid-ı9 são notórios, tanto nas enzimas, receptores e demasiadamente em até nos sintomas. Por isso deve ser feito uma melhor análise de ambos os grupos para não haver um falso diagnóstico. Já existem nas mídias digitais, nos rótulos dos produtos o quanto o tabaco é prejudicial, mas vale investir em orientar a população em relação ao início de sintomas para que haja uma devida intervenção pessoal e médica.

\section{REFERÊNCIAS}

Barua RS, Sy F, Srikanth S, Huang G, Javed U, Buhari C, Margosan D, Ambrose JA. Effects of cigarette smoke exposure on clot dynamics and fibrin structure: an ex vivo investigation. Arterioscler Thromb Vasc Biol. 2010 Jan;30(I):75-9. doi: Io.ı16I/ATVBAHA.I09.195024. Epub 2009 Oct 8. PMID: 198158I6.

Brake SJ, Barnsley K, Lu W, McAlinden KD, Eapen MS, Sohal SS. Smoking upregulates angiotensin-converting enzyme-2 receptor: a potential adhesion site for novel coronavirus SARS-CoV-2 (Covid-I9). J Clin Med 2020; 9:E84I.

Cai H. Sex difference and smoking predisposition in patients with COVID-19. Lancet Respir Med 2020; 8: e20

CARVALHO MALTA, Deborah et al. social distancing, feeling of sadness and lifestyles of the Brazilian population during the COVID-I9 pandemic. In: Social distancing, feeling of sadness and lifestyles of the Brazilian population during the COVID-I9 pandemic. 2020. CAVAlCANTE, Tânia Maria et al. Covid-ı́ e tabagismo: aspectos epidemiológicos, biológicos, psicossociais e implicações para a Política Nacional de Controle do Tabaco. Revista Brasileira de Cancerologia, v. 66, n. TemaAtual, 2020. 
Changeux JP, Amoura Z, Rey FA, Miyara M. A nicotinic hypothesis for Covid-I9 with preventive and therapeutic implications. C R Biol. 2020 Jun 5;343(I):33-39. doi: 10.5802/crbiol.8. PMID: 32720486.

Chiusano ML. The modelling of COVIDig pathways sheds light on mechanisms, opportunities and on controversial interpretations of medical treatments. v2. arXiv 2003.11614 [Preprint]. 2020 Mar 25 [cited 2020 Apr 22]: [ 15 p.]. Available from: https://arxiv.org/ftp/arxiv/papers/2003/2003.11614.pdf

CRODA, Julio Henrique Rosa; GARCIA, Leila Posenato. Resposta imediata da Vigilância em Saúde à epidemia da COVID-ı9. Epidemiol. Serv. Saúde, Brasília , v. 29, n. I, ezozoooz, 2020 . Available from <http://www.scielo.br/scielo.php?script=sci_arttext\&pid=S223796222020000100100\&lng=en\&nrm=iso>. access on I3 May 2021. Epub Mar 23, 2020. https://doi.org/10.5123/si679-4974202000o100021.

DE ARAÚJO, Alberto José. A dependência do tabaco na pandemia e a relevância da associação COVID-ı9 e tabaco. Pulmão RJ, v. 29, n. I, p. 28-31, 2020.

de Lusignan S, Dorward J, Correa A, Jones N, Akinyemi O, Amirthalingam G, Andrews N, Byford R, Dabrera G, Elliot A, Ellis J, Ferreira F, Lopez Bernal J, Okusi C, Ramsay M, Sherlock J, Smith G, Williams J, Howsam G, Zambon M, Joy M, Hobbs FDR. Risk factors for SARS-CoV-2 among patients in the Oxford Royal College of General Practitioners Research and Surveillance Centre primary care network: a cross-sectional study. Lancet Infect Dis. 2020 Sep;20(9):1034-1042. doi: 10.1016/Si473-3099(20)30371-6. Epub 2020 May I5. PMID: 32422204; PMCID: PMC7228715.

Liu W, Tao ZW, Wang L, Yuan ML, Liu K, Zhou L, Wei S, Deng Y, Liu J, Liu HG, Yang $\mathrm{M}, \mathrm{Hu} \mathrm{Y}$. Analysis of factors associated with disease outcomes in hospitalized patients with 2019 novel coronavirus disease. Chin Med J (Engl). 2020 May 5;133(9):1032-1038. doi: I0.1097/CM9.0000000000000775. PMID: 32118640; PMCID: PMC7147279. 
MALTA, Deborah Carvalho et al. Fatores associados ao aumento do consumo de cigarros durante a pandemia da COVID-ı́ na população brasileira. Cad. Saúde Pública, Rio de Janeiro , v. 37, n. 3, e00252220, 2021 . Available from $<$ http://www.scielo.br/scielo.php?script=sci_arttext\&pid=Soro23IIX2021000300506\&lng=en\& $\mathrm{nrm}=$ iso $>$. access on 13 May 2021. Epub Apr 07, 2021. http://dx.doi.org/10.1590/o102-311x00252220.

Organização Mundial de Saúde (OMS). WHO Director-General's opening remarks at the media briefing on COVID-ı-II March 2020. Genebra: OMS [internet]. 2020 [acesso em 202I jun I4]. Disponível em: https://www.who.int/dg/speeches/detail/who-directorgeneral-s-opening-remarks-at-the-media-briefing-on-covid-ı---II-march-2020

Patanavanich R, Glantz SA. Smoking Is Associated With COVID-19 Progression: A Metaanalysis. Nicotine Tob Res. 2020 Aug 24;22(9):1653-1656. doi: 10.1093/ntr/ntaao82. PMID: 32399563; PMCID: PMC7239135.

RAMOS, Mariana et al. Abordagem do tabagismo nos grupos de sala de espera como estratégia de promoção à saúde. Brazilian Journal of Health Review, v. 4, n. 2, p. 5476-5488, 202I.

Sardu, C.; Gambardella, J.; Morelli, M.B.; Wang, X.; Marfella, R.; Santulli, G. Is COVIDI9 an Endothelial Disease? Clinical and Basic Evidence. Preprints 2020, 2020040204 (doi: I0.20944/preprints202004. 0204.vi).

SILVA, Andre Luiz Oliveira da; MOREIRA, Josino Costa; MARTINS, Stella Regina. COVID-ı́ e tabagismo: uma relação de risco. Cadernos de Saúde Pública, v. 36, p. e00072020, 2020.

SZKLO, André Salem. Associação entre fumar e progressão para complicações respiratórias graves em pacientes com Covid-19. Revista Brasileira de Cancerologia, v. 66, n. 2, 2020. 
SZKLO, André Salem; BERTONI, Neilane. Relação entre a Epidemia de Tabagismo e a Epidemia recente de Covid-ı9: um Panorama Atual das Evidências Científicas. Revista Brasileira de Cancerologia, v. 66, n. TemaAtual, 2020.

Tindle HA, Newhouse PA, Freiberg MS. Beyond Smoking Cessation: Investigating Medicinal Nicotine to Prevent and Treat COVID-19. Nicotine Tob Res. 2020 Aug 24;22(9):1669-1670. doi: 10.1093/ntr/ntaao77. PMID: 32383751; PMCID: PMC723914I.

University of California Merced [Internet]. Merced (CA): c2020. Morgante M. COVIDI9 more likely to impact smokers and people exposed to secondhand smoke, report finds; 2020 Apr 2 [cited 202I May 6]. Available from: https://news.ucmerced.edu/news/2020/covid-I9-more-likely-impact-smokers-and-peopleexposed-secondhand-smoke-report-finds

WHO Framework Convention on Tobacco Control [Internet]. Beirut: FCTC; c2org. Najen J. Increased risk of COVID-ıg infection amongst smokers and amongst waterpipe users; 202I May I2I]. Available from: https://untobaccocontrol.org/kh/waterpipes/covid-19/)

World Health Organization. Preventing noncommunicable diseases [Internet]. WHO, 2020 [citado 12 de maio de 202I]; available from: https://www.who.int/activities/preventing-noncommunicable-diseases/tobacco-kills-8million-people-every-year 